University of Nebraska - Lincoln

DigitalCommons@University of Nebraska - Lincoln

U.S. Environmental Protection Agency Papers

U.S. Environmental Protection Agency

2007

\title{
Application of the US decision support tool for materials and waste management
}

Susan A. Thorneloe

U.S. EPA, thorneloe.susan@epa.gov

Keith Weitz

RTI International, kaw@rti.org

Jenna Jambeck

University of New Hampshire - Main Campus, jenna.jambeck@unh.edu

Follow this and additional works at: https://digitalcommons.unl.edu/usepapapers

Thorneloe, Susan A.; Weitz, Keith; and Jambeck, Jenna, "Application of the US decision support tool for materials and waste management" (2007). U.S. Environmental Protection Agency Papers. 181.

https://digitalcommons.unl.edu/usepapapers/181

This Article is brought to you for free and open access by the U.S. Environmental Protection Agency at DigitalCommons@University of Nebraska - Lincoln. It has been accepted for inclusion in U.S. Environmental Protection Agency Papers by an authorized administrator of DigitalCommons@University of Nebraska - Lincoln. 


\title{
Application of the US decision support tool for materials and waste management
}

\author{
Susan A. Thorneloe ${ }^{\mathrm{a}, *}$, Keith Weitz ${ }^{\mathrm{b}}$, Jenna Jambeck ${ }^{\mathrm{c}}$ \\ ${ }^{a}$ US EPAIOffice of Research and Development, National Risk Management Research Laboratory, Air Pollution Prevention and Control \\ Division (MD E305-02), Research Triangle Park, NC, USA \\ ${ }^{\mathrm{b}}$ RTI International, Research Triangle Park, NC, USA \\ ${ }^{\mathrm{c}}$ Department of Civil/Environmental Engineering, University of New Hampshire, Durham, NH, USA
}

Accepted 16 February 2007

Available online 12 April 2007

\begin{abstract}
The US Environmental Protection Agency (US EPA) launched the Resource Conservation Challenge (RCC) in 2002 to help reduce waste and move towards more sustainable resource consumption. The objective of the RCC is to help communities, industries, and the public think in terms of materials management rather than waste disposal. Reducing cost, finding more efficient and effective strategies to manage municipal waste, and thinking in terms of materials management requires a holistic approach that considers life-cycle environmental tradeoffs. The US EPA's National Risk Management Research Laboratory has led the development of a municipal solid waste decision support tool (MSW-DST). The computer software can be used to calculate life-cycle environmental tradeoffs and full costs of different waste management or materials recovery programs. The environmental methodology is based on the use of life-cycle assessment and the cost methodology is based on the use of full-cost accounting. Life-cycle inventory (LCI) environmental impacts and costs are calculated from the point of collection, handling, transport, treatment, and disposal. For any materials that are recovered for recycling, offsets are calculated to reflect potential emissions savings from use of virgin materials. The use of the MSW-DST provides a standardized format and consistent basis to compare alternatives. This paper provides an illustration of how the MSW-DST can be used by evaluating ten management strategies for a hypothetical medium-sized community to compare the life-cycle environmental and cost tradeoffs. The LCI results from the MSW-DST are then used as inputs into another US EPA tool, the Tool for the reduction and assessment of chemical and other environmental impacts, to convert the LCI results into impact indicators. The goal of this paper is to demonstrate how the MSW-DST can be used to identify and balance multiple criteria (costs and environmental impacts) when evaluating options for materials and waste management. This type of approach is needed in identifying strategies that lead to reduced waste and more sustainable resource consumption. This helps to meet the goals established in the US EPA's Resource Conservation Challenge. Published by Elsevier Ltd.
\end{abstract}

\section{Introduction and background}

The need for credible and science-based information for making more informed waste management decisions precipitated the development of a decision-support tool for municipal waste. Often decision makers are faced with conflicting and incomplete information that can have major

\footnotetext{
* Corresponding author. Tel.: +1 919541 2709; fax: +1 9195417885.

E-mail addresses: thorneloe.susan@epa.gov (S.A. Thorneloe), kaw@ rti.org (K. Weitz), jenna.jambeck@unh.edu (J. Jambeck).
}

economic and environmental implications. In the US, more than 214 million metric tons of municipal solid waste (MSW) was generated in 2003 and more than US\$40 billion was spent on its management (US EPA, 2003a). Finding more efficient options can help reduce cost and reduce environmental burdens.

The US EPA recognizes the need for finding flexible, yet protective, ways to conserve national resources. The resource conservation challenge (RCC) was launched in 2002 to help the US move away from solid waste and think more in terms of "materials" management (US EPA, 
$2003 \mathrm{~b}, 2004)$. This is to be done through: (1) pollution prevention, recycling, and reuse of materials; (2) reduction of the use of toxic chemicals; and (3) conservation of energy and materials. The objectives are to encourage more sustainable resource use and to minimize waste. The MSWDST helps support the goals for the RCC by identifying materials/waste management strategies that balance resource consumption, environmental burdens, and cost. The MSW-DST can also be used to identify the "best" management option for individual materials (Thorneloe and Weitz, 2001, 2003, 2004).

With the transition from waste management to materials management, it is even more important to have tools available that consider life-cycle environmental tradeoffs. Determining the best means to manage solid waste is not straightforward. Questions that arise include: should food waste be composted or landfilled? Should newsprint be recycled, landfilled, or combusted? What is the environmental benefit or burden from increasing the recycling rate in a community or adopting a curbside recycling program? What about increased air pollution from waste collection and transport? Is it better to export waste to a larger regional facility or continue use of an existing near-by facility that may not have the same degree of environmental controls? Are there changes within a community's existing infrastructure that could improve efficiency and reduce cost and environmental burdens?

The economics of solid waste management are also becoming increasingly important as communities face higher energy costs, and competing priorities. To address budgetary concerns, recycling programs are often targeted for reduction and even elimination, which occurred in New York city (it was later restored). Are there potential savings from finding more regional solutions to solid waste management? If so, then what are the actual savings in terms of reduced costs and environmental burdens?

The MSW-DST was developed through a partnership between Federal, state, and local government, the private sector, and environmental interest groups. The goal of this research was to develop information and a computer program and supporting database to evaluate the relative cost and environmental performance of integrated MSW management strategies. The primary audience for the outputs is local government and solid waste planners. However, the outputs are also of value to Federal agencies, environmental and solid waste consultants, industry, LCA practitioners, and environmental advocacy organizations.

Over 80 stakeholders were active participants in the development of the process models and tool. Funding for the research was provided by the US EPA and the US Department of Energy. The work was conducted through a cooperative agreement between the US EPA's National Risk Management Research Laboratory (NRMRL) and RTI International (Thorneloe et al., 1999a; Thorneloe and Weitz, 2001, 2003). The research team included North Carolina State University (NCSU) who had a major role in the development of the LCI and cost models as well as
MSW-DST. The University of Wisconsin was responsible for development of the life-cycle inventory (LCI) data and process models for mixed MSW and yard waste composting (Komilis and Ham, 1999, 2000; Ham and Komilis, 2003). Funding was also provided by the Environmental Research and Education Foundation (EREF) for the development of LCI data and process models for municipal solid waste landfills (Ecobalance, 1999). The methodology, process models, MSW-DST, and documentation went through extensive review including that of stakeholders, a series of external peer-reviews, in addition to peer, quality assurance, and US EPA administrative review.

To account for differences in environmental benefits for recycling different MSW components, research was also conducted to develop LCI data sets for aluminium, glass, plastic, paper, and steel. RTI International worked in cooperation with private-sector partners, environmental interest groups, Franklin Associates, and Roy F. Weston to develop the LCI datasets. Each industry sector provided review and/or LCI data. Extensive effort was put into ensuring comparability of the LCI data. Environmental interest groups were also active participants in the development and review of LCI data including the Environmental Defense and the Natural Resources Defense Council (Weitz, 2003; Thorneloe and Weitz, 2003).

Fig. 1 provides an illustration of the MSW life-cycle. All activities are considered from the point of collection to ultimate disposition, whether that be in a landfill, compost that is applied to the land, energy that is recovered from combustion, or materials that are recovered and reprocessed into new products. The computer software can track up to 26 components (e.g., yard waste, food waste, paper, plastic, metals, and glass) from residential, multi-family dwellings, and commercial sectors. Differences in MSW composition and management can be tracked for these different sectors helping to identify where they may offer more environmental benefit or cost savings from expanding recycling programs or making improvements to existing waste management programs.

The MSW-DST provides a standard approach for evaluating the life-cycle environmental tradeoffs and full costs of MSW management. Over 40 unit processes have been modeled covering waste collection, transportation, materi-

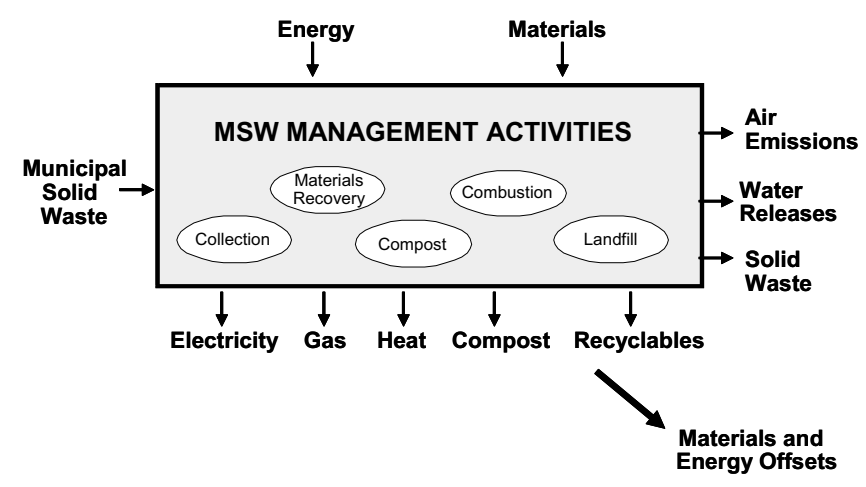

Fig. 1. Illustration of MSW life-cycle. 


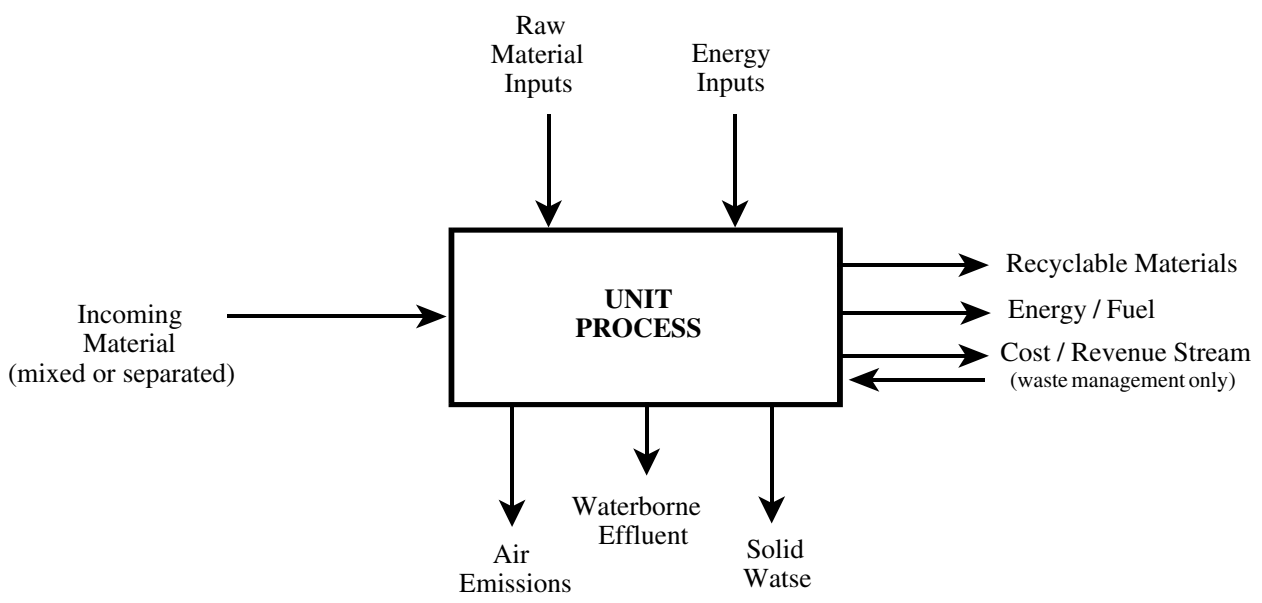

Fig. 2. Illustration of a unit process A given quantity and composition of material flows into each unit process. Default facility designs and operating conditions are used to estimate the energy and resource use, environmental releases, and cost (or revenue) for each unit process. These values are then partitioned to individual MSW components using the allocation provided in Table 2.

als recovery, transfer stations, treatment, and disposal. An illustration of a unit process is provided in Fig. 2. A list of the unit processes is provided in Table 1 . The process models calculate the cost, energy consumption and LCI emissions for 32 pollutants from each solid waste unit operation based on the quantity and composition of waste processed. Each process model contains peer-reviewed default values that can be adjusted to reflect site-specific data. The allocation of cost, resource and energy consumption, and environmental releases for individual MSW components is described in Table 1 for each unit process.

Over 50 applications of the tool have been conducted on community, state, and national basis (Thorneloe and Weitz, 2001, 2003, 2004; Barlaz et al., 2003a,b; Weitz et al., 1999). The tool was used in a study for the State of California to compare waste conversion technologies.

Table 1

Process model assumptions and allocation procedures

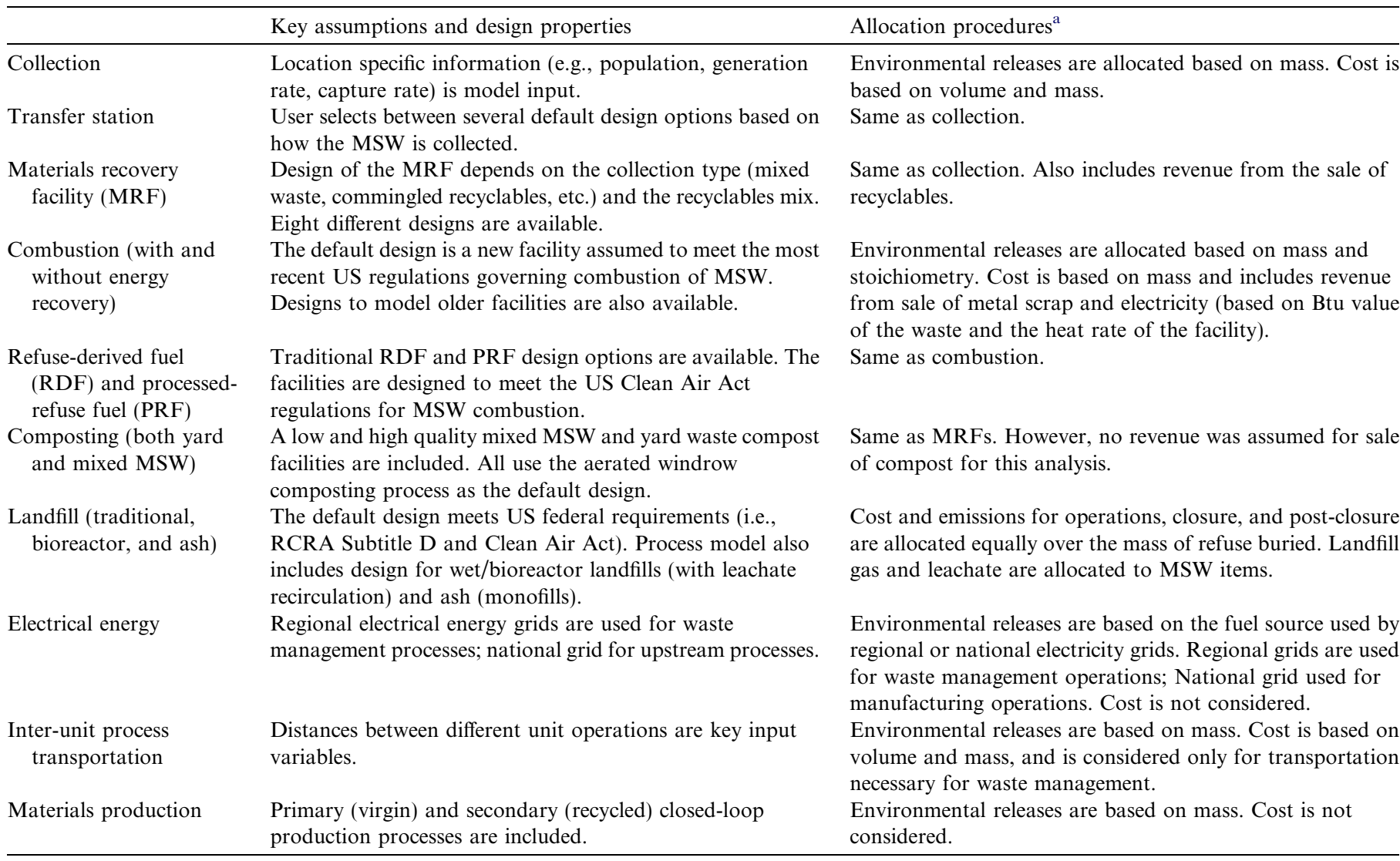

${ }^{a}$ Allocation of costs, resource and energy consumption, and environmental releases to individual MSW components. 
Several other studies are underway in helping communities develop solid waste management plans and improving the environmental benefit or cost of recycling programs. Studies have varied from just comparing different options for waste collection and transportation to identifying options that help maximize recycling targets. Some studies have been conducted that evaluate the relationship between waste management and greenhouse gas emissions (Weitz et al., 2002). A study was conducted to compare the lifecycle environmental burdens between disposal and combustion of CCA-treated wood (Jambeck et al., 2007). The MSW-DST is available through either RTI International or NCSU for conducting studies. A web accessible version of the MSW-DST (which is a simplified version) is under development. The web accessible version is expected to be released in 2007 once final reviews have been completed.

Different materials (i.e., aluminum cans, green glass, newsprint, office paper, PET beverage containers, steel cans, and yard trimmings) have different LCI burdens depending upon extraction of raw materials, materials processing, manufacturing, use, and waste management. Accounting for these differences helps communities identify which components to target for recycling programs to help maximize environmental and economic benefits. The MSW-DST provides the methodology, LCI data, and other information for making these evaluations through a comprehensive mathematical model that accounts for cost, energy, and environmental emissions. The model is implemented through an interactive decision support system (Harrison et al., 2001). This type of analysis helps communities to identify more sustainable solutions that minimize environmental burdens and maximize resource conservation and recovery (Coleman et al., 2003; McDougall et al., 2001; White et al., 1995).
Table 2

Description of scenarios used to illustrate potential environmental and economic tradeoffs

\begin{tabular}{|c|c|}
\hline Scenario & Description \\
\hline 1 & $10 \%$ recycling, $90 \%$ landfilled with no gas collection and control. \\
\hline 2 & $20 \%$ recycling, $80 \%$ landfilled with no gas collection and control. \\
\hline 3 & $30 \%$ recycling, $70 \%$ landfilled with no gas collection and control. \\
\hline 4 & $40 \%$ recycling, $60 \%$ landfilled with no gas collection and control. \\
\hline 5 & $\begin{array}{l}30 \% \text { recycling, } 70 \% \text { landfilled; landfill gas is collected and } \\
\text { combusted using flare. }\end{array}$ \\
\hline 6 & $\begin{array}{l}30 \% \text { recycling, } 70 \% \text { landfilled; landfill gas is combusted using } \\
\text { internal combustion engines to produce electricity. }\end{array}$ \\
\hline 7 & $\begin{array}{l}30 \% \text { recycling, } 70 \% \text { landfilled; landfill gas is piped to nearby } \\
\text { industrial facility and combusted in boiler (displacing fuel oil). }\end{array}$ \\
\hline 8 & $\begin{array}{l}30 \% \text { recycling, } 70 \% \text { combusted using waste to energy facility } \\
\text { (generating electricity and recovery of metals). }\end{array}$ \\
\hline 9 & $\begin{array}{l}\text { Same as Scenario } 5 \text { except waste is collected and transported to } \\
\text { transfer station, and then long-hauled } 800 \mathrm{~km} \text { ( } 500 \text { miles) to } \\
\text { landfill using semi-tractor truck. }\end{array}$ \\
\hline 10 & Same as Scenario 9 except waste is long-hauled to landfill by rail. \\
\hline
\end{tabular}

The purpose of this paper is to illustrate the use of the MSW-DST for evaluating different MSW management strategies. The scenarios, identified in Table 2, were selected to help illustrate the change in LCI environmental tradeoffs with increased materials recovery; differences in landfill gas capture and control, waste combustion with energy recovery; and differences in waste transport. The scenario analysis also helps to document environmental improvements from strategies that are now more typical in the US (Scenarios 5 through 10) versus what was more typical in the 1970s (Scenario 1) with minimal recycling and control of landfill gas. The scenarios were calculated for a medium size community with a population of 750,000 and a waste generation rate of approximately $1.6 \mathrm{~kg}(3.5 \mathrm{lb})$ per person per day (US EPA, 2003a,b).

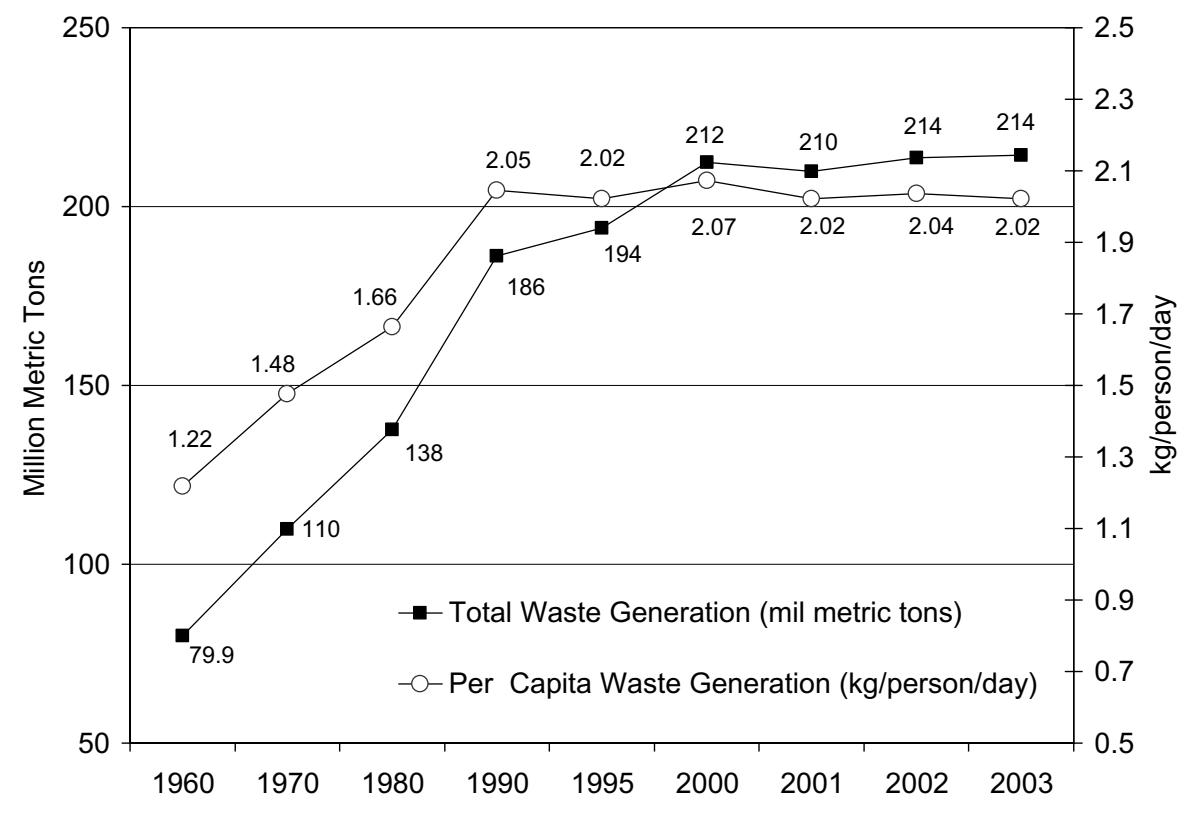

Fig. 3. Trends in US MSW generation (US EPA, 2003a,b). 
2. MSW management scenarios and MSW-DST input data

Data from the US EPA's Office of Solid Waste were used to model the ten scenarios that were defined in Table 2. As of 2003, the amount of municipal waste generated in the US was 214 million metric tons or $2 \mathrm{~kg} /$ person/day (Fig. 3; US EPA, 2003a). Statistics on waste composition and materials recovery rates are also available through the US EPA (Fig. 4; US EPA, 2003a). Paper is the largest component in municipal waste with $37 \%$ ( 79 million metric tons). Of the paper that is collected, $45 \%$ is recycled ( 40 million metric tons). Yard waste represents $12 \%$ of the total waste. Of the yard waste that is collected, $57 \%$ is composted (15 million metric tons). The national average recycling rate, which includes composting is $30 \%$ (Fig. 5; US EPA, 2003a, 2005). The Resource Conservation Challenge has identified a recycling goal of $35 \%$ for the US by 2005 (US EPA, 2004). Recent statistics for the U.S. for the year 2005 indicated that total materials recovery was at $32 \%$. However, the amount of discards being landfilled decreased from $89 \%$ in 1980 to $54 \%$ in 2005 (US EPA, 2006).

The ten scenarios were defined (Table 2) to help compare environmental and economic tradeoffs between different waste management practices. The first four scenarios illustrate the transition between minimal recycling as was done in the 1970s versus increasing recycling to $40 \%$. The discards are landfilled at a site without any control to help capture the changes with increasing the rate of materials recovery. With each increase, different waste components are captured optimizing on the least cost. Figure 6 provides the composition of materials that are recovered for each scenario. The fifth scenario is typical of most US cities with
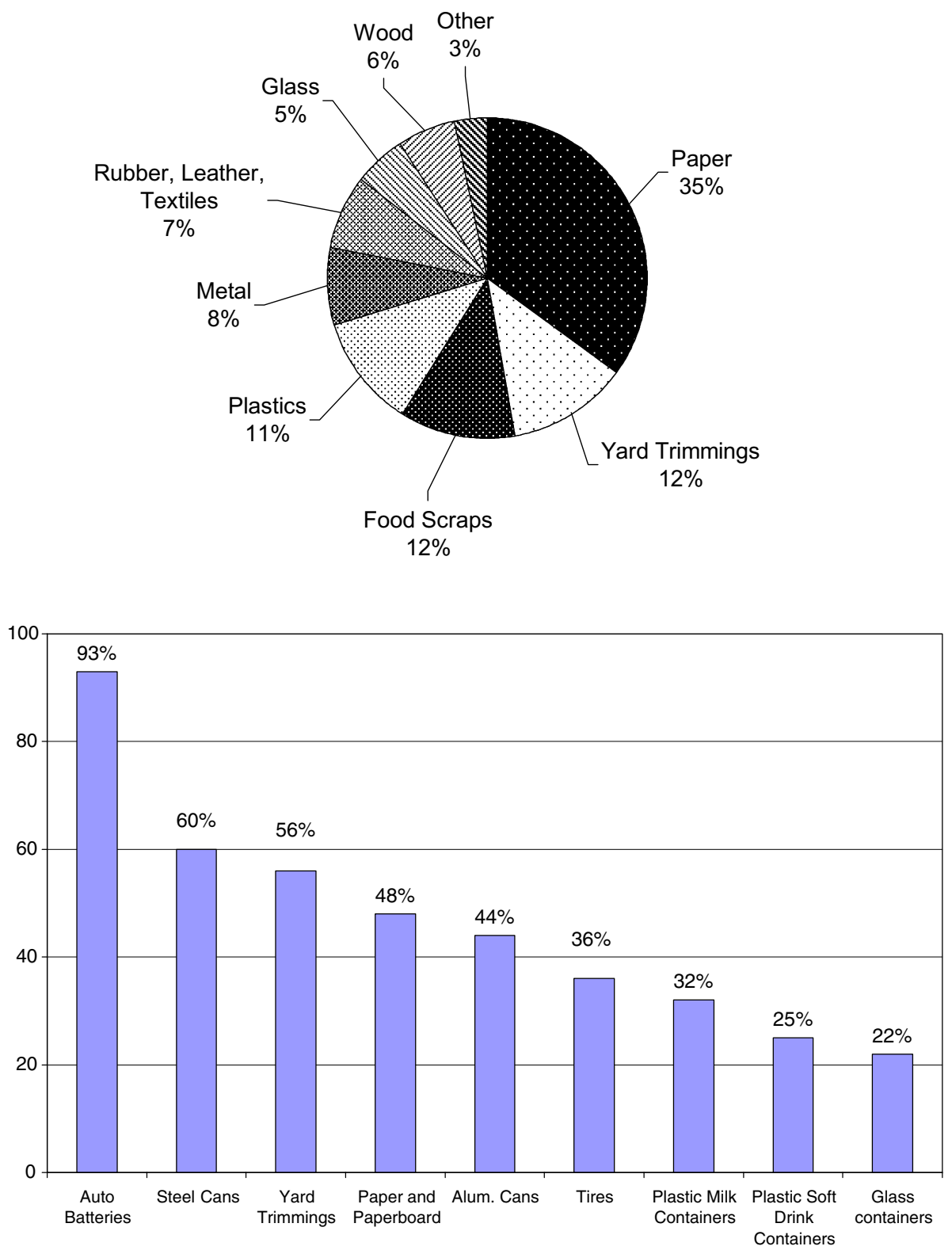

Fig. 4. Composition of MSW in the US and selected recycling rates (US EPA, 2003a, 2005). 


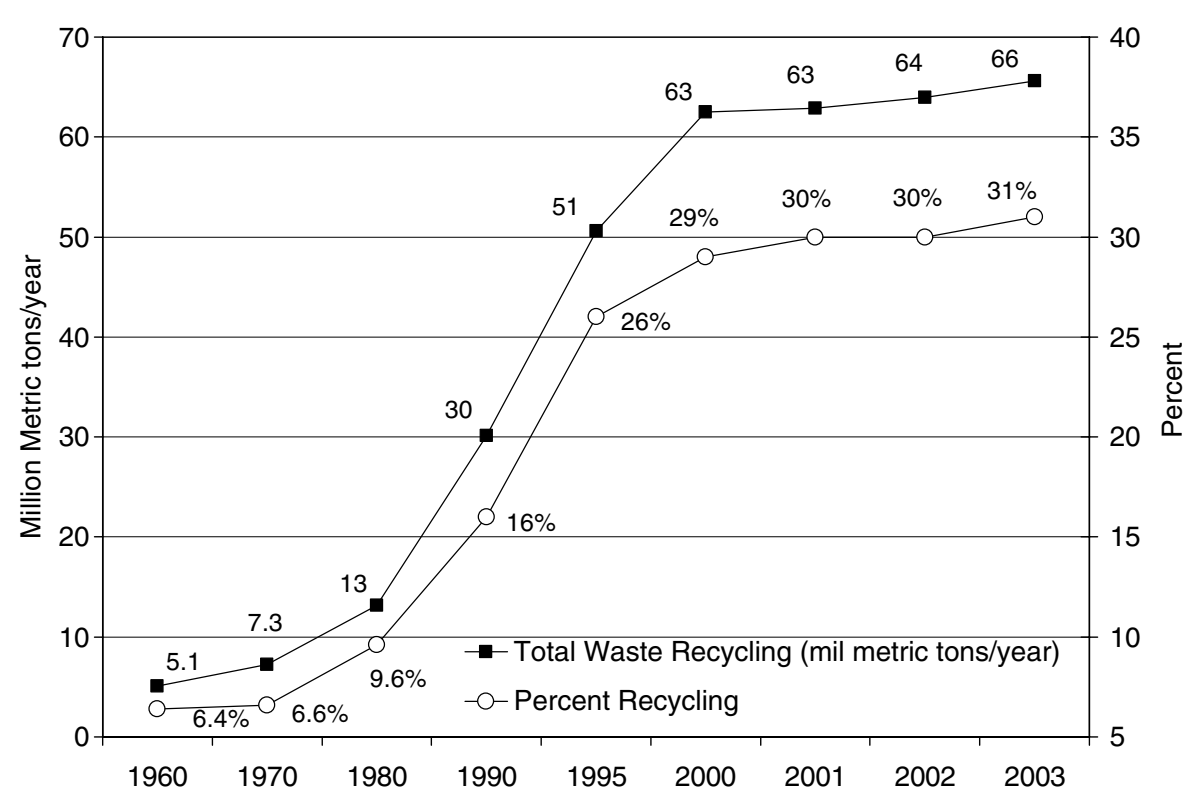

Fig. 5. US waste recycling rates 1960-2001 (US EPA, 2003a).

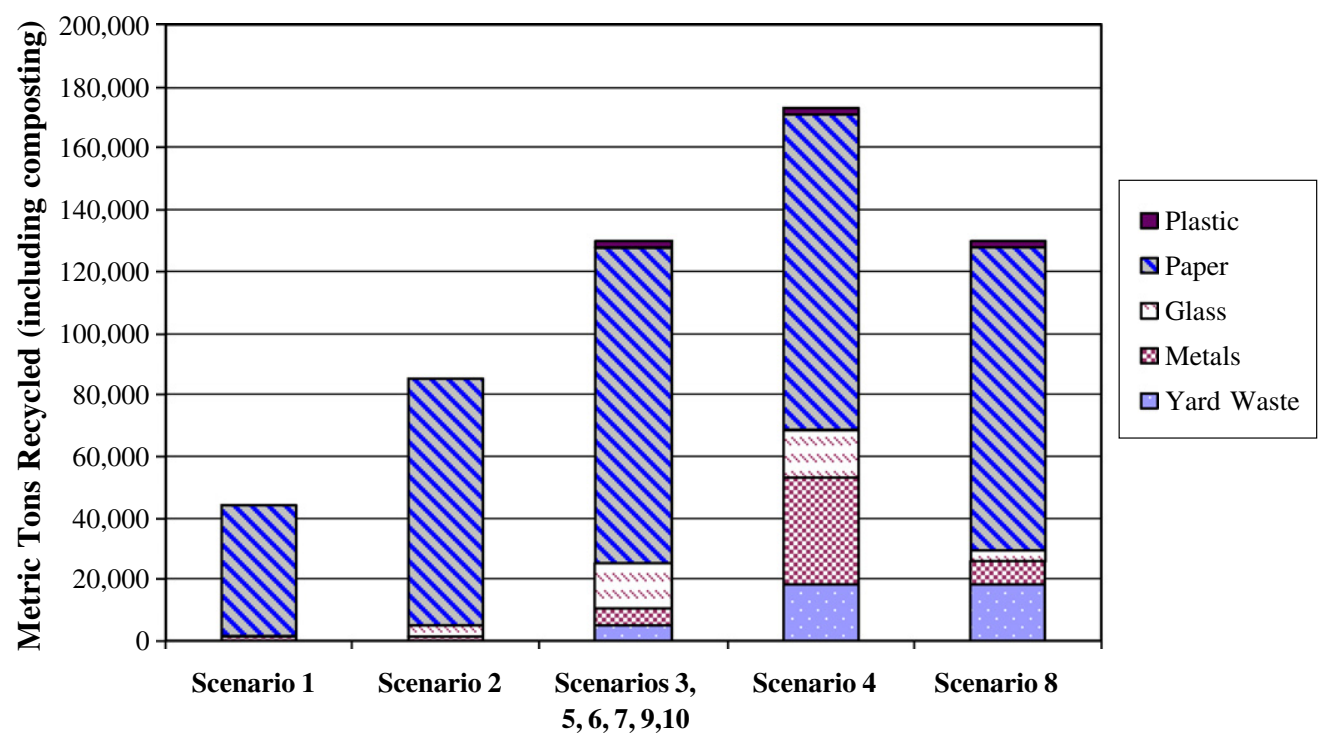

Fig. 6. Composition of materials captured by tonnage for management scenarios.

a 30\% recycling rate and discards being landfilled. For this scenario, the landfill gas is controlled and flared. The next two scenarios were selected to quantify the benefit of landfill gas recovery to produce electricity (Scenario 6) and to offset fuel oil in nearby industrial plant (Scenario 7). Approximately $14 \%$ (or 29,000 million metric tons) of MSW in the US is combusted with energy recovery. Scenario 8 represents a typical waste-to-energy (WTE) facility in the US which recovers any metals in the ash and meets stringent Clean Air Act requirements. The last two scenarios were chosen to help illustrate the differences in environmental impacts when waste is hauled long distances using semi-tractor trucks (Scenario 9) or rail (Scenario 10). These scenarios are identical to Scenario 5 except that the waste is hauled to a transfer station prior to transport $800 \mathrm{~km}$ to a landfill. This operation is becoming more frequent in the US with the closing of smaller, older landfills and the use of larger, more modern, regional landfills. These scenarios do not account for all of the diversity that exists in different geographical regions of the US They also do not account for differences that exist between urban, suburban, and rural communities. However, these scenarios are thought to help illustrate the differences in waste or materials management strategies that are thought to have the greatest impact on life-cycle environmental tradeoffs or costs.

The same quantity of solid waste was used for each scenario $(437,000$ metric tons/yr), which is considered to be a medium-sized community in the US with a population of 
750,000 . Weekly collection of waste and recyclables was assumed, with all items collected on the same day from residential, multi-family, and commercial sectors. The waste composition is based on national averages (Fig. 4). Costs were calculated using model defaults, which reflect national and regional averages. Key assumptions for each process model are identified in Table 3.

The diversion rates in each scenario were met through a combination of recycling and yard waste composting. The MSW-DST uses linear optimization software to find the most efficient solution based on minimum cost or environmental objective (e.g., minimum release of greenhouse gases) (Solano et al., 2002a, 2002b). Multiple criteria can be used which could combine cost and environmental objectives to find more efficient solutions for waste and materials management. For this analysis, cost was used in

Table 3

Summary of key assumptions used in this study

\begin{tabular}{ll}
\hline Parameter & Assumption \\
\hline $\begin{array}{l}\text { General } \\
\text { Waste generation }\end{array}$ & 437,000 metric tons/yr \\
$\begin{array}{l}\text { Waste composition } \\
\text { Collection frequency }\end{array}$ & $\begin{array}{l}\text { National average } \\
1 \text { time per week }\end{array}$ \\
$\begin{array}{l}\text { Transportation distance } \\
\text { Collection to transfer station }\end{array}$ & $16 \mathrm{~km}$ one way \\
Collection to MRF & $16 \mathrm{~km}$ one way \\
Collection to compost & $16 \mathrm{~km}$ one way \\
Collection to WTE & $16 \mathrm{~km}$ one way \\
Collection to landfill & $16 \mathrm{~km}$ one way \\
Transfer station to landfill & $800 \mathrm{~km}$ one way (used in long-haul \\
& scenarios)
\end{tabular}

Materials recycling facility

Basic design

Equipment

Separation efficiency

Compost facility

Basic design

Windrow turning frequency

Compost residence time

Compost curing time

WTE facility

Basic design

Heat rate

Waste input heating value

Ferrous metal recovery rate

Utility sector offset

Semi-automated, commingled recyclables

Magnet, eddy-current separator, glass crusher

$90 \%$ for all materials

Yard waste, windrow

$2270 \mathrm{~kg} /$ week

168 days

90 days

Mass burn

$18,600 \mathrm{~kJ} / \mathrm{kWh}$

Varies by waste constituent

$90 \%$

Baseload coal

Landfill

Basic design

Subtitle D

Time period for calculating emissions

Landfill gas collection efficiency

Landfill gas management

Utility sector offset

$100 \mathrm{yr}$

$75 \%$

Varied (vent, flare, and energy recovery)

Baseload coal (for ICE) or fuel oil (for boiler).

${ }^{\text {a From EPA's Office of Solid Waste (http://www.epa.gov/msw/ }}$ msw99.htm). identifying which mix of components would meet the diversion goals set in each scenario (i.e., we solved for the least cost mix that would meet scenario goals). The analysis did not try to maximize resource conservation and recovery although this has been done in previous publications (Barlaz et al., 1999b; Harrison et al., 2001). Therefore, this will be sensitive to the market value for recyclables. When used for a site-specific analysis or in solid waste management planning, different values can be used to reflect current prices and to evaluate market impacts on management practices.

The mix of materials that were captured by the $10 \%$, $20 \%, 30 \%$, and $40 \%$ recycling goals is presented in Fig. 6 . The $10 \%$ diversion rate was met by using recycling only (i.e., no yard waste composting). The recycling consisted of commingled recyclables from residential and multi-family housing and presorted recyclables from commercial entities. To reach the $20 \%, 30 \%$, and $40 \%$ diversion rates (or recycling goals), the model included both recycling and yard waste composting from the residential sector. Note that for reaching a $40 \%$ recycling target, there is almost $100 \%$ capture of metals.

Modeling of energy has been found to have a significant impact on the life-cycle environmental tradeoffs (Finnveden et al., 2002). Energy emissions include extraction, production, consumption, and offsets for energy conservation. In the US the marginal energy source to be displaced is typically coal-fired power plants (Weitz et al., 2002). Therefore, the energy offsets that were used for Scenarios 6 and 8 are for coal combustion. For Scenario 7, the most likely offset is fuel oil which was used in calculating the energy offset.

Assumptions regarding landfill gas control can also have a significant impact (Ecobalance, 1999; Barlaz et al., 1999a). For the scenarios with landfill gas control (i.e., Scenarios 4, 5, 7-10), a landfill gas collection efficiency of $75 \%$ was assumed. This is consistent with the US EPA's guidelines for developing emission inventories (US EPA, 1997). However, some sites will obtain greater capture efficiency while some sites may have less. Most large landfills in the US (i.e., greater than 2.5 million tons of waste) collect and control landfill gas. However, some sites exist that are below the size threshold for the Clean Air Act gas control requirements (i.e., they do not have gas control). However, the trend in the US is towards larger, regional landfills with gas control. About 400 US landfills have energy recovery (US EPA, 2007). Life-cycle environmental emissions and costs were calculated over a 100 -year time frame. More detail on the life-cycle landfill model is provided in a report that was prepared for the Environmental Research and Education Foundation (Ecobalance, 1999).

More detailed descriptions of how individual waste management processes are modeled have been provided in previous publications (Barlaz et al., 1999a,b; Ham and Komilis, 2003; Harrison et al., 2001; Thorneloe and Weitz, 2001, 2003; Weitz, 2003). Key process model assumptions and allocation procedures are summarized in Table 2. 


\section{Results and discussion}

The standard output of the MSW-DST is annualized cost, energy consumption, and life-cycle environmental emissions for 32 pollutants (Solano et al., 2002a,b). The life-cycle emissions data were used as inputs to the US EPA's Tool for the Reduction and Assessment of Chemical and other Environmental Impacts (TRACI, Version 2.0) (Bare, 2002; Bare et al., 2003). TRACI is computer software that allows storage of inventory data, classification of stressors, and characterization of impact categories within various life-cycle stages. Impact categories include climate change, acidification, eutrophication, trospospheric ozone, and human and ecosystem health.

\subsection{Cost}

The cost results generated by the MSW-DST are based on a full cost accounting (FCA) approach. This is a systematic approach for accounting for past and future costs, overhead (oversight and support services) costs, and operating costs. Historically, cash flow accounting has been used by local government to track the flow of financial resources regardless of when the money is spent. This does not reflect the time value of money which is needed to compare waste management alternatives or any option where there are past and future costs to be accounted for.

Waste management can involve significant expenditures both before and after the operating life of management facilities. Focusing solely on the use of current financial resources will misrepresent the actual cost of MSW management. For example, a landfill includes the cost of permitting, design, construction, operation, and long-term monitoring. In full cost accounting, all of these costs are included when calculating the net annualized costs (Ecobalance, 1999).
Another advantage is that system-wide costs are being compared (collection, transport, materials recovery facility, treatment, and disposal). In addition, the market value of recyclables is also factored in. Many of these parameters can vary over time and within different geographical regions. The defaults in the tool can be adjusted to account for site-specific values such as labor rates, land values, regional market prices for recyclables and energy, and any special permit requirements for licensing a facility. The information can also be used to benchmark the costs to compare to similar communities or norms.

Fig. 7 provides a comparison of the total net (i.e., cost minus revenues from the sale of materials and/or energy) annual cost for the 10 scenarios analyzed. The lowest cost scenario is Scenario 2 at $20 \%$ recycling and the remainder is landfilled. As recycling is increased to $30 \%$ and $40 \%$ in scenarios 3 and 4 , the cost increases by $42 \%$ and $69 \%$, respectively, because it becomes more difficult and costly to recover the marginal recyclable (given a fixed infrastructure). Similarly, when the rate of recycling is reduced to $10 \%$ in Scenario 1, the cost increases. This suggests that there are cost benefits of increasing recycling levels past $10 \%$ but diminishing returns somewhere in the $20-30 \%$ range (assuming fixed infrastructure, recycling program participation, and separation efficiencies). The highest cost management option is the WTE scenario (Scenario 8).

\subsection{Energy consumption}

The results for total net energy consumption are shown in Fig. 8. All scenarios show a net negative energy consumption which highlights the significance of materials recycling in terms of energy consumption. Even recycling at the $10 \%$ level in Scenario 1 results in a net energy savings over the total system. As shown in Fig. 8, the energy

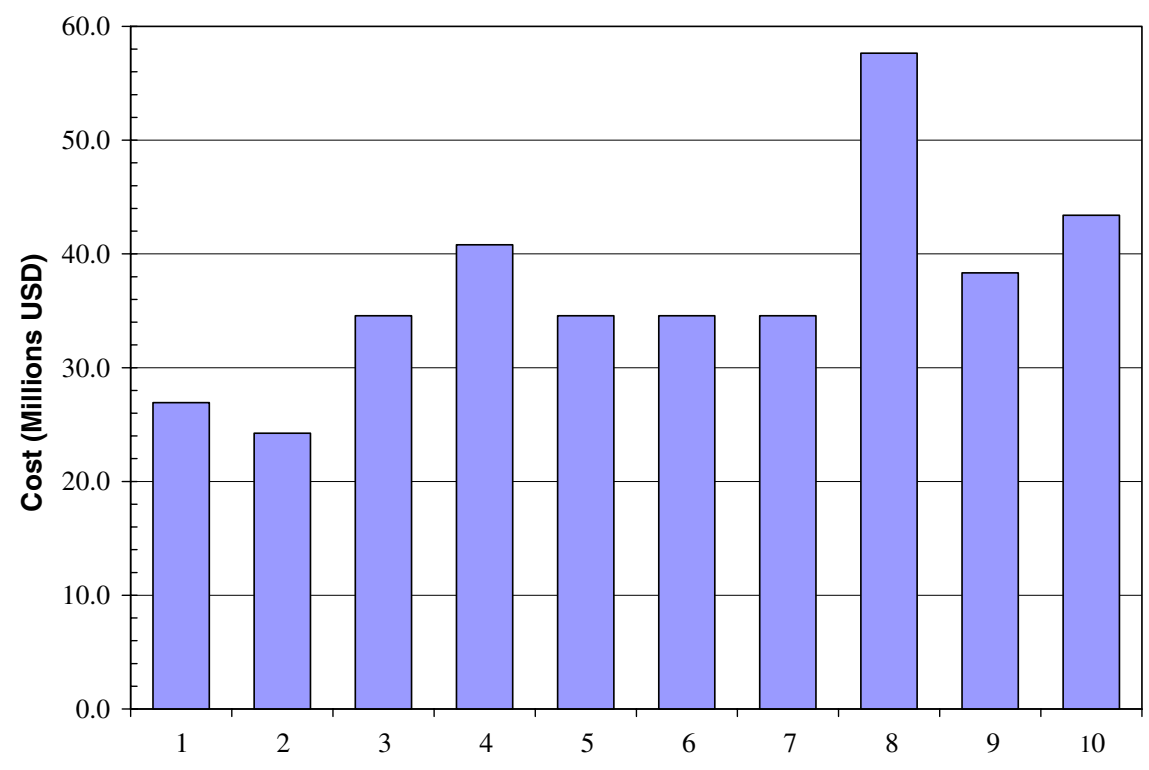

Fig. 7. Net annualized cost by scenario (in US\$). 


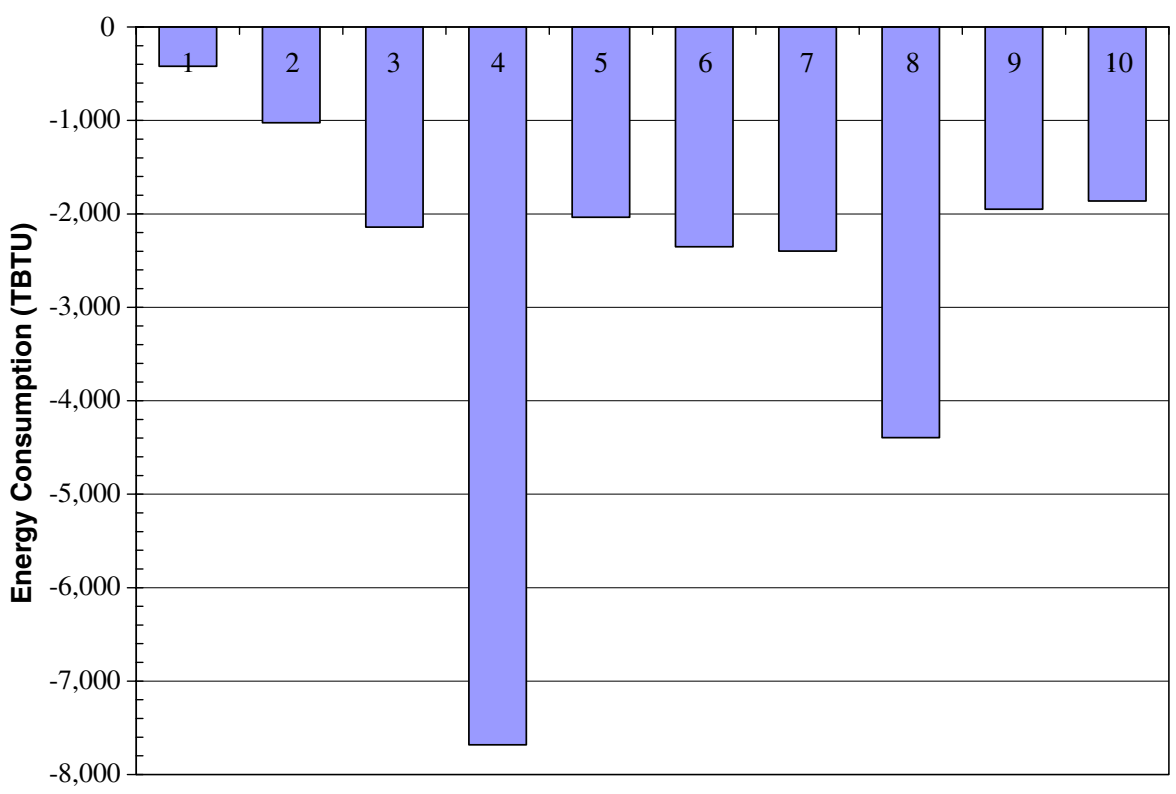

Fig. 8. Net energy consumption by scenario.

savings are largest with the higher recycling level $(40 \%$ for Scenario 4) and where energy recovery is greatest (in the Scenario 8 WTE). The large jump in energy savings between the $30 \%$ and $40 \%$ recycling scenarios is due largely to the addition of metals recycling in Scenario 4 to meet the $40 \%$ rate. Metals' recycling has a high energy savings potential compared to most other recyclables. If another material (or mix of materials) had been used to meet the $40 \%$ recycling rate, the energy savings likely would not have increased as much. The specific material that the MSW-DST selects for inclusion in recycling portion was based on a minimum cost criterion. Therefore, the least cost items to recycle are selected first to meet the recycling target. The higher cost of metals recycling is likely due to the longer distances for transporting metals to remanufacturing facilities as compared to the other materials.

\subsection{Climate change}

Fig. 9 presents a comparison of the net carbon emissions using MSW-DST life-cycle emissions results for methane and carbon dioxide as inputs to TRACI. The results from TRACI are in units of grams of $\mathrm{CO}_{2}$ equivalent. These units were converted to kilograms of $\mathrm{CO}_{2}$ equivalent for presentation in Fig. 9. Previous research shows that as waste management technologies have evolved, greenhouse gas (GHG) emissions have been reduced (Weitz et al., 2002). This study shows similar results. The first four scenarios illustrate recycling benefits increasing from $10 \%$ to $40 \%$ recovery with no residuals being landfilled. For these four scenarios, no landfill gas control was assumed. The transition between these scenarios and Scenario 5 helps illustrate the importance of landfill gas control. A significant reduction in greenhouse gases can be achieved

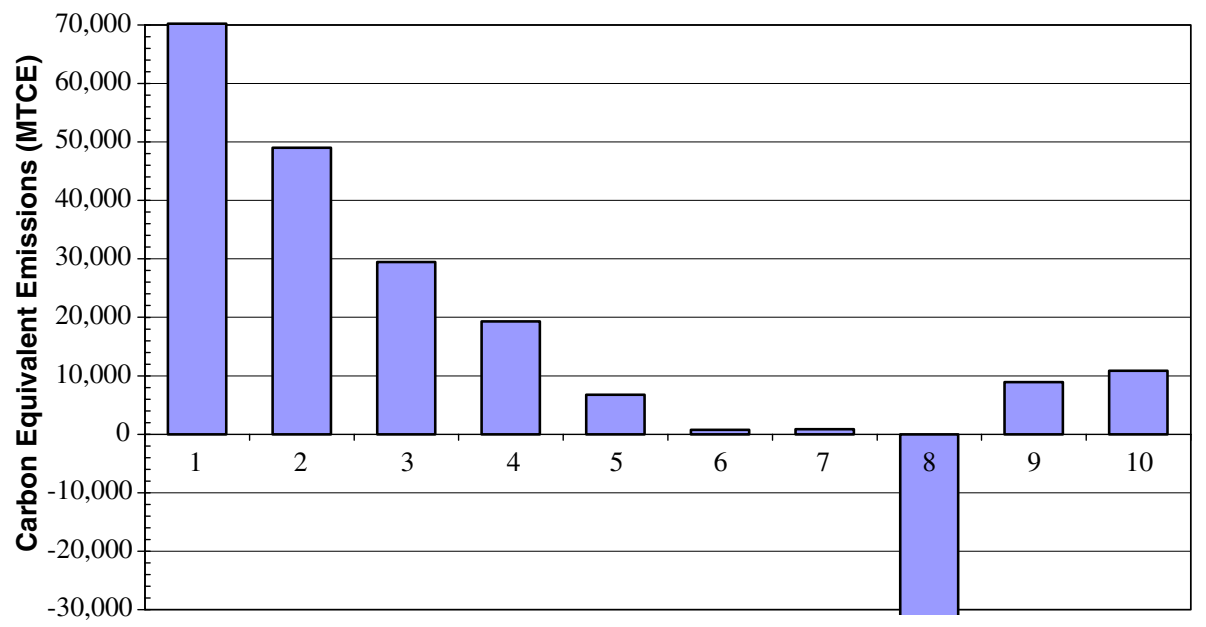

Fig. 9. Net global climate change emissions by scenario. 
through increased recycling and control of landfill gas. About 300 US landfills have energy recovery (Thorneloe and Weitz, 2001).

The most attractive strategy from a GHG perspective is Scenario 8 . The negative offset is due to energy conservation, increased metals recovery, and absence of landfilling any biodegradable waste (only residual being landfilled is combustion ash).

Scenarios 9 and 10 provide the GHG impact of long hauling using either semi-tractor trailers or rail. In the US, there is an increasing trend towards transporting waste over long-distances. Typical distances vary from 480 to $800 \mathrm{~km}$ (300-500 miles). As smaller, older landfills reach capacity and are closed, communities are often transporting waste over longer distances. Typically, waste is collected and transported to a transfer station where the waste is compacted for long haul using either semi-tractor trailers or rail. For the rail-haul, typically there is a transfer station at both ends of the rail line. For this analysis, a long-haul distance of $800 \mathrm{~km}$ (500 miles) was assumed. The results show a slight increase in GHG emissions for long-haul transport as compared to Scenario 5 where waste is transported to near-by landfill.

\subsection{Acidification}

The pollutants calculated by the MSW-DST that contribute to acidification include SOx, NOx, ammonia, and $\mathrm{HCl}$. These pollutants are tied to: (1) fuel combustion, and (2) electrical energy production and consumption (including mining of coal or raw materials extraction). The results in Fig. 10 for acidification increase or decrease from scenario to scenario depending on how much fuel and electrical energy are consumed. TRACI was used to model acidification based on moles of $\mathrm{H}+$ equivalents. The results for all scenarios are negative, indicating a net savings or avoidance of acidification related pollutants for each scenario. The negative values are directly tied to materials and/or energy recovery from the scenarios.

The WTE scenario (Scenario 8) shows the greatest offset of acidification-related pollutants, primarily because it results in the largest energy offset. One might expect that the $40 \%$ recycling scenario, which had the greatest net energy offset, would also have the greatest acidification offset. However, it appears that while the addition of metals recycling saves a significant amount of energy, it does not necessarily save as much in terms of acid precursors. This may be due to the longer transportation distances for metals remanufacturing and/or emissions during the remanufacturing processes. There is also an increase in the offset of acidification that results from landfill gas to energy projects (see Scenario 5 versus Scenarios 6 and 7). Scenarios 9 and 10 show the negative affects that long-hauling waste have in terms of acidification.

\subsection{Eutrophication}

Eutrophication results based on grams of nitrogen equivalents using TRACI indicate a net savings or avoidance of eutrophication related pollutants for each scenario. The pollutants that contribute to acidification include NOx and ammonia air emissions. Waterborne pollutants that contribute to eutrophication include ammonia, biochemical oxygen demand (BOD), chemical oxygen demand (COD), and phosphate. Phosphate releases appear to be the most significant and are predominantly tied to materials remanufacturing. Thus, the results for eutrophication will generally increase or decrease from scenario to scenario depending on the quantity and type of material recycled.

Paper production and remanufacturing appear to be the key material driving the eutrophication results. Paper recycling is increased significantly from Scenario $1(10 \%$ recycling) to Scenario $2(20 \%$ recycling) and then remains relatively constant through the remaining scenarios and thus the eutrophication results also follow this pattern See Fig. 11.

\subsection{Trospospheric ozone (or smog)}

TRACI's model for smog is based on grams of NOx equivalents. The results presented in Fig. 12 indicate a

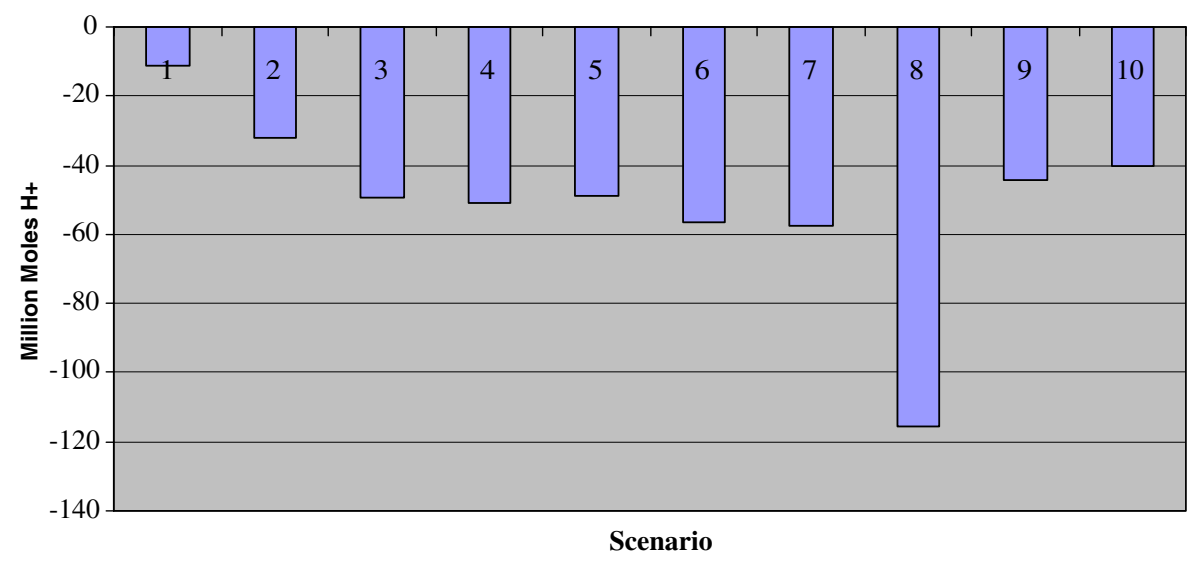

Fig. 10. Acidification results by scenario 


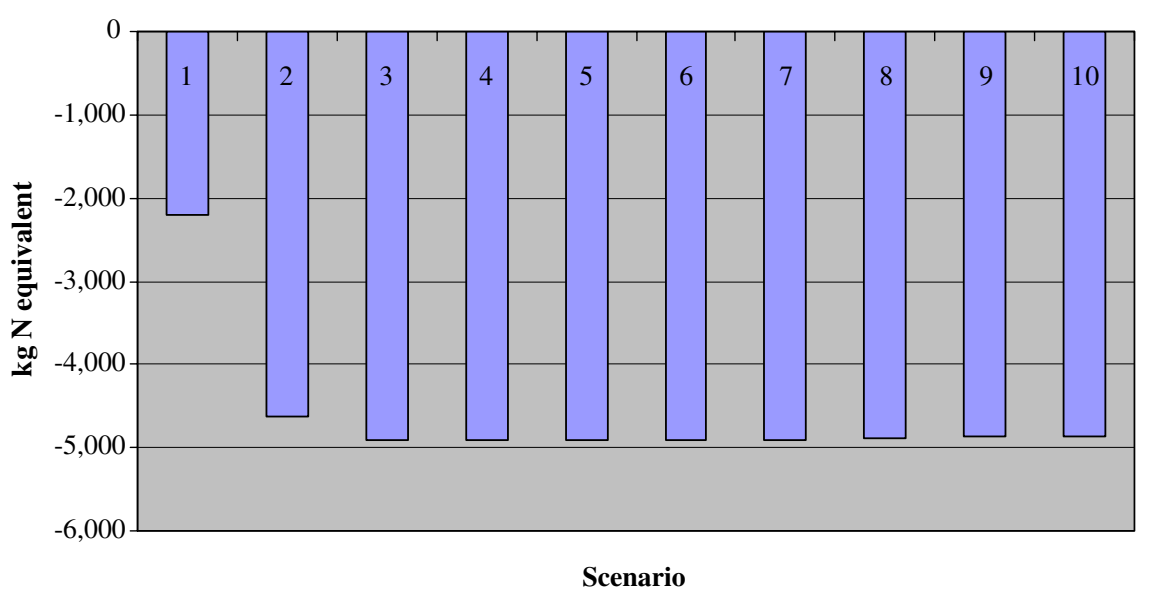

Fig. 11. Eutrophication results by scenario.

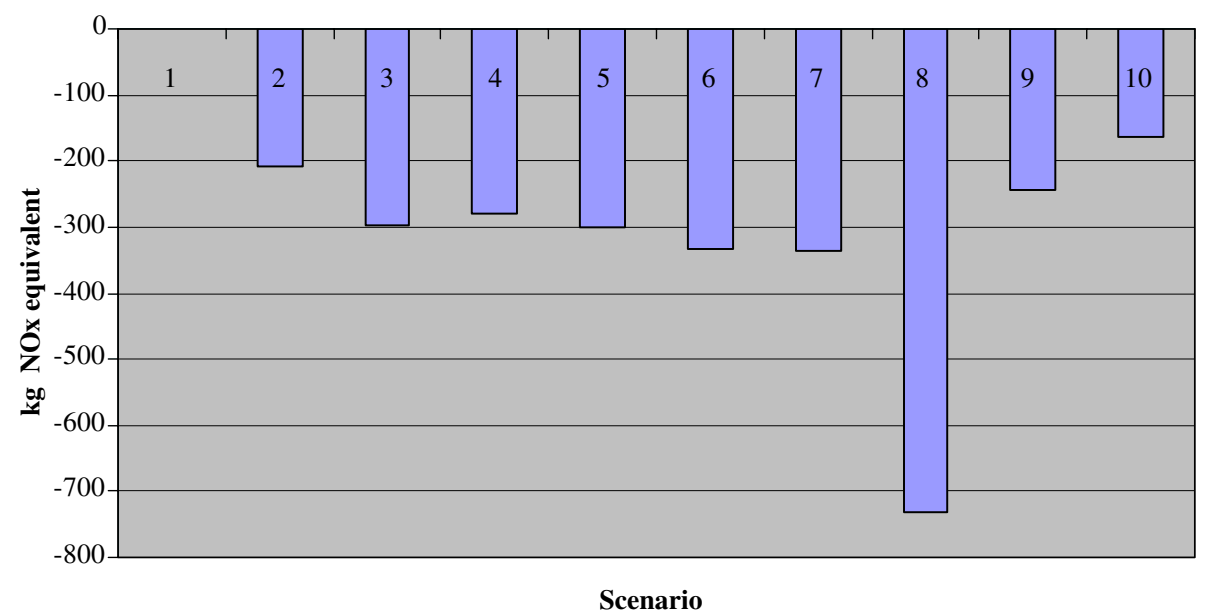

Fig. 12. Smog results by scenario.

net reduction or avoidance of smog related pollutants for each scenario. The pollutants that contribute to smog formation include NOx, carbon monoxide and methane with NOx being the most potent of the smog forming pollutants. NOx and carbon monoxide emissions are generally tied to the combustion of fuels while methane emissions are largely tied to the degradation of organic material in landfills. Although methane emissions from landfills are quite large, their smog equivalent is relatively low. This is illustrated when comparing Scenario 3 (where landfill gas is vented) to scenarios 5 through 7 (where landfill gas is controlled). The results for smog are most significantly governed by transportation related activities and materials recycling (in general). Thus, an increase or decrease from scenario to scenario will depend on how much fuel and electrical energy are consumed. The negative values are directly tied to materials and/or electrical energy recovery from the scenarios.

The WTE scenario (Scenario 8) shows the greatest offset of smog related pollutants because it offsets the most electrical energy. One might expect that the $40 \%$ recycling sce- nario, which had the greatest net energy offset, would also have the greatest smog offset. However, it appears that while the addition of metals recycling saves a significant amount of energy, it does not necessarily save as much in terms of smog related gases. There is also a slight increase in the offset of smog that results from landfill gas to energy projects (see Scenario 5 versus scenarios 6 and 7). Scenarios 9 and 10 show the negative affects that long-hauling waste have in terms of smog production.

\subsection{Human health}

Human health impacts are modeled in TRACI for cancer, non-cancer, and criteria pollutant categories. The indicator used for each of these categories is as follows (1) cancer: grams of benzene equivalent; (2) non-cancer: grams of toluene equivalent; and (3) criteria: grams PM2.5 equivalent. For presentation purposes, TRACI results were converted to kilograms of respective equivalent. The results for the three human health categories are shown in Figs. 13-15. 


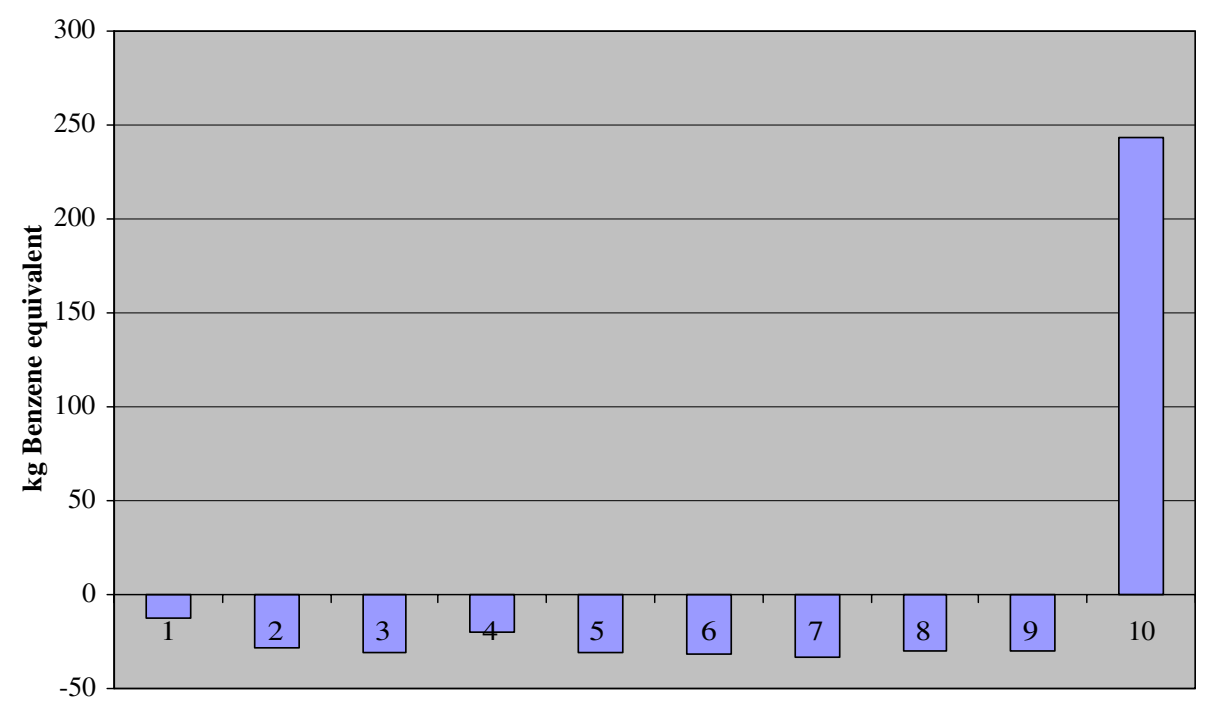

Scenario

Fig. 13. Human health cancer results.

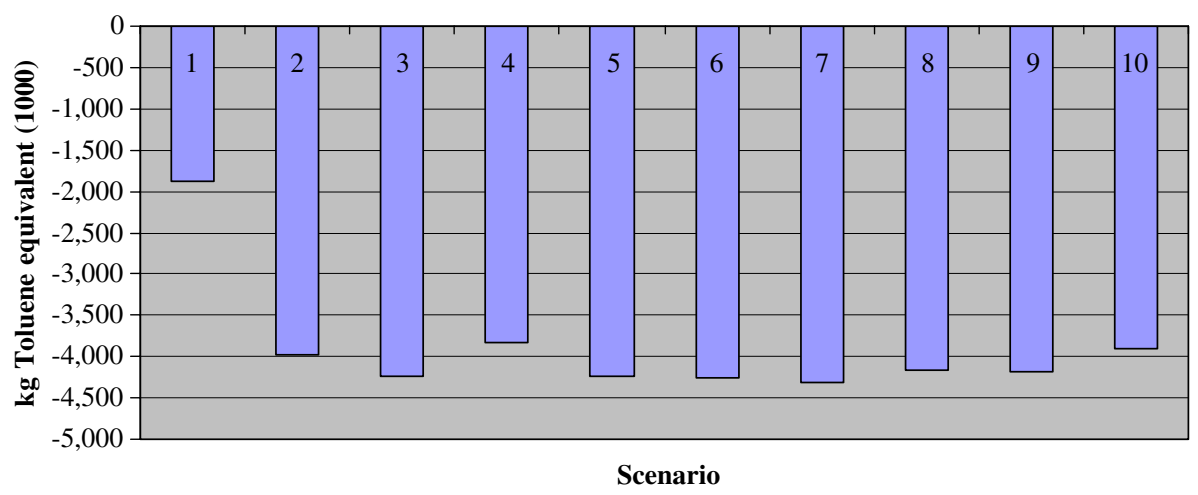

Fig. 14. Human health non-cancer results.

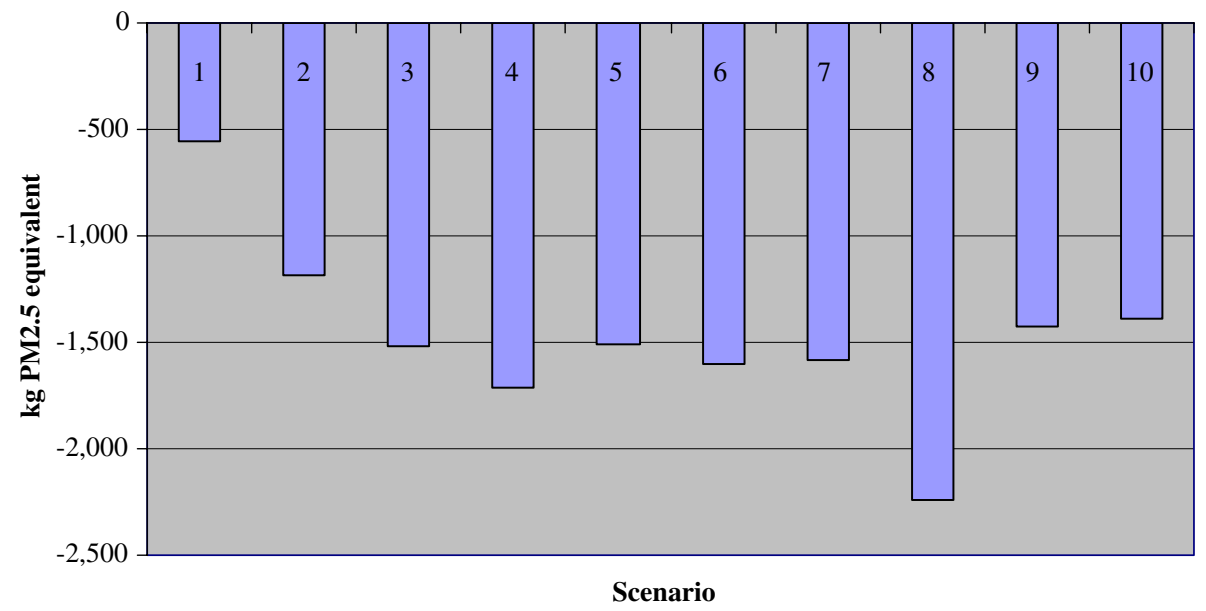

Fig. 15. Human health criteria air pollutant results.

The key pollutants reported by the MSW-DST to model cancer impacts include lead releases to the air and water and arsenic and cadmium releases to water. Of these pollutants, arsenic is the most potent cancer agent. However, it is insig- nificant relative to lead and cadmium releases. Fig. 13 indicates relatively little difference between the scenarios for cancer related health effects except for Scenario 10 which transports waste using long-haul by rail. This is related to 


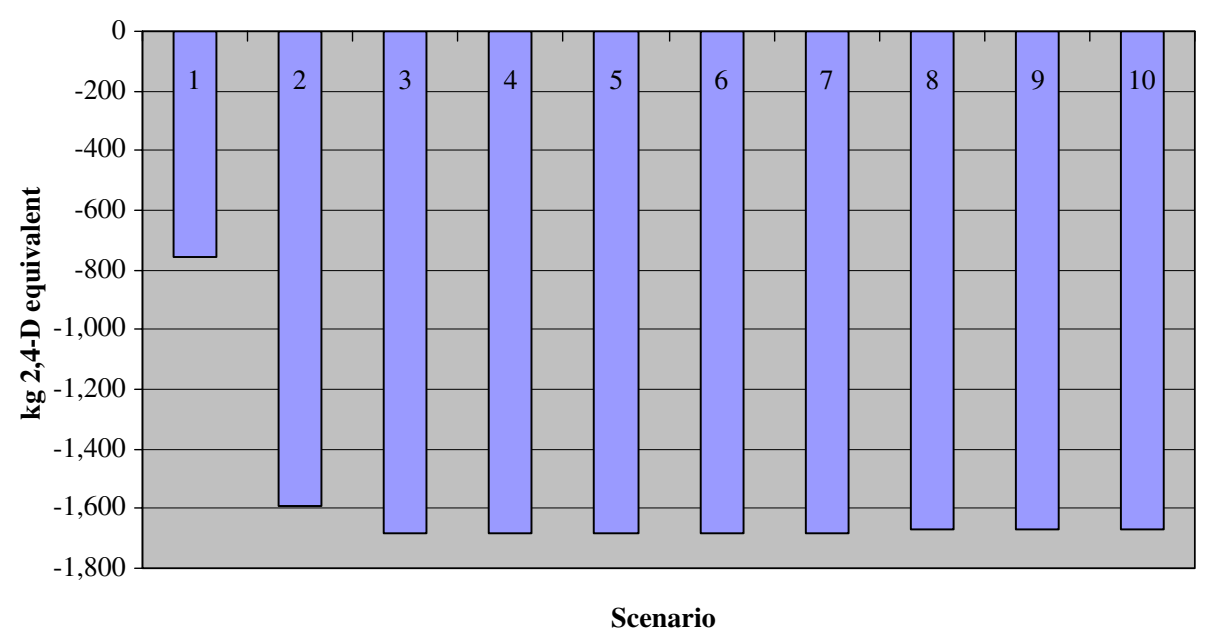

Fig. 16. Ecological toxicity results.

higher cadmium and lead water releases associated with the production and combustion of fuel for rail engines.

For non-cancer human health impacts (Fig. 14), the results are negative for all scenarios because of a net offset of non-cancer related pollutants. The non-cancer pollutants reported by the MSW-DST and used in the non-cancer TRACI model include air releases of ammonia, $\mathrm{HCl}$, and lead and water releases of iron, ammonia, copper, cadmium, arsenic, mercury, selenium, lead, and zinc. The pollutant that appears to drive this non-cancer category is zinc through water releases. In reviewing the LCI results, zinc releases (or in this case offset of releases) result from materials remanufacturing operations and thus the results are tied to materials recycling. Specifically, paper recycling is driving the non-cancer health results. As paper recycling increases from Scenario 1 to 2, the non-cancer health offset increases but as paper recycling remains steady for the remaining scenarios, the non-cancer results also remain steady.

For criteria pollutants, the TRACI model converts US EPA criteria air pollutants to PM 2.5 equivalents. Fig. 15 shows the criteria pollutant human health results for this study based on life-cycle emission results from the MSWDST for PM, SOx, and NOx. All results are negative indicating that there is a net savings or avoidance of criteria air emissions for all scenarios. In reviewing the LCI results, these air emissions (or in this case offset of releases) result from materials remanufacturing operations as well as electrical energy consumption/production and thus the results are generally tied to these two activities. The WTE scenario (Scenario 8 ) has the highest offset due to its 30\% recycling and high recovery of electrical energy from the remaining portion of the waste stream. Scenario 1 has the lowest net offset because it has the lowest level of recycling.

\subsection{Ecological toxicity results}

For ecological toxicity, TRACI converts specific pollutants (air and water) to grams of 2,4-D equivalents. The results presented in Fig. 16 are reported in kilograms. All scenarios indicate a net offset of eco-tox related pollutants. The eco-toxicity pollutants reported by the MSW-DST and used as inputs in the TRACI model include: (1) ammonia, $\mathrm{HCl}$, and lead for air releases and (2) iron, ammonia, copper, cadmium, arsenic, mercury, and selenium for water releases.

In reviewing the TRACI equivalency factors and results, it appears that zinc releases to the water are the driving pollutant for eco-tox and thus the results are directly tied to this pollutant. In reviewing the LCI results, zinc releases (or in this case offset of releases) result from materials remanufacturing operations and thus the results are tied to materials recycling. Specifically, paper recycling is driving the non-cancer health results. As paper recycling increases from Scenario 1 to 2, the eco-tox offset increases but as paper recycling remains steady for the remaining scenarios, the non-cancer results also remain steady.

\section{Conclusion}

With the US EPA's Resource Conservation Challenge, there is increased interest in finding more sustainable solutions for waste management. This paper provides an evaluation of scenarios to illustrate the tradeoffs in life-cycle emissions, energy consumption, and micro-economic costs between different strategies for waste and materials management. The results are based on a medium-sized community using national or average defaults. Cost results capture the full-costs of managing the defined tonnage of waste through its life (varies by waste management operation). Environmental results capture the full life cycle burdens and benefits of waste and materials management. Although actual results for a specific community will vary, the general trends are thought to be realistic. The use of MSWDST in evaluating management strategies can help a community identify site-specific strategies that maximize environmental benefits and minimize cost.

Multi-criteria analysis did not result in any clear winner. For example, WTE appears to be the most attractive 
option in terms of net carbon emissions, acidification, and smog. However, this option had a higher cost as compared to the other options using landfills. The option with the lowest cost is Scenario 2 which had a $20 \%$ recycling rate. The option with the most attractive net energy consumption is the option with a $40 \%$ recycling target. This is due to offsets from primary production, which includes extraction and mining environmental burdens.

In general the recovery of materials and energy helps to reduce environmental impacts, as illustrated by the results. Criteria based on improving environmental and economic performance would have to be developed on a site-specific basis to help determine which scenario is preferred depending upon a community's objectives and constraints. Some communities may have greater concern over water quality issues whereas others may value air quality concerns more. Constraints to consider include whether there is sufficient waste to fuel a WTE plant or available land to build a landfill. Uncertainty is also a factor and important in decision making (Kaplan et al., 2005 ) to be considered in future analysis. In a cursory review of the results, Scenario $6(30 \%$ recycling, residual landfilled, and landfill gas recovered to produce electricity using IC engines) might be viewed as preferred because of its mid-range cost, $30 \%$ recycling rate, and life-cycle environmental performance. However, if environmental performance was given more weight than cost, then one might prefer Scenario $8(30 \%$ recycling rate and residual managed using WTE facility).

How might this analysis change for a given community? The results could be quite different when model defaults for land values, labor rates, facility costs, and environmental burdens are adjusted to represent site-specific values. The results presented in this paper are based on a limited number of pollutants. For some options, metals, hazardous air pollutants, and toxics, are calculated for some options (e.g., combustion and landfills) but not for all because there is no consistent data across all options. Also, the remanufacturing numbers seem to dominate the impact results. It would be interesting (perhaps in a future paper) to separate the impacts from waste activities from those associated with energy and materials production.

Next steps include conducting further applications of the MSW-DST for regional and local decision making. Work on a web-accessible version of the MSW-DST is also progressing. Once reviews are complete, a web-accessible version will be released (planned for 2007) providing easier access and more wide-spread use. The web accessible version is to include TRACI for allowing impact assessment for comparing materials and waste management strategies. Updates will be conducted as newer data and information become available.

\section{References}

Bare, J., 2002. Developing a consistent decision-making framework by using the US EPA's TRACI, presented at American Institute of
Chemical Engineers Symposium. <http://www.epa.gov/ORD/ NRMRL/std/sab/traci/>.

Bare, J., Norris, G., Pennington, D., McKone, T., 2003. TRACI - the tool for the reduction and assessment of chemical and other environmental impacts. Journal of Industrial Ecology 6 (3-4).

Barlaz, M.A., Camobreco, V., Repa, E., Ham, R.K., Felker, M., Rousseau, C., Rathle, J., 1999a. Life-Cycle Inventory of a Modern Municipal Solid Waste Landfill, Sardinia 99. In: Seventh International Waste Management and Landfill Symposium, vol. III, p. 337-344 (Oct 4-8).

Barlaz, M.A., Ranjithan, S.R., Brill, E.D. Jr., Dumas, R.D., Harrison, K.W., Solano, E., 1999b. Development of Alternative Solid Waste Management Options: A Mathematical Modeling Approach, Sar 99, Seventh Int. Waste Management \& Landfill Symp., Vol I, 25-32, Oct 4-8.

Barlaz, M.A., Kaplan, P.O., Ranjithan, S.R., Rynk, R., 2003a. Evaluating environmental impacts of solid waste management alternatives, Part I. Biocycle (Sept.), 60-66.

Barlaz, M.A., Kaplan, P.O., Ranjithan, S.R., Rynk, R., 2003b. Evaluating environmental impacts of solid waste management alternatives, Part II. Biocycle (Oct.), 52-56.

Coleman, T., Masoni, P., Dryer, A., McDougall, F., 2003. International expert group on life cycle assessment for integrated waste management. Journal of LCA 8 (3).

Ecobalance, 1999. Life-cycle inventory of a modern municipal solid waste landfill; prepared for the Environmental Research and Education Foundation, Washington, DC.

Finnveden, G., Nilsson, M., Johansson, J., Persson, A., Moberg, A., Carlsson, T., 2002. Strategic Environmental Assessment Methodologies - Applications within the Energy Sector. Environmental Impact Assessment Review 23 (91-123).

Ham, R.K., Komilis, D., 2003. A laboratory study to investigate gaseous emissions and solids decomposition during composting of municipal solid waste, EPA-600/R-03/004.

Harrison, K.W., Dumas, R.D., Solano, E., Barlaz, M.A., Brill, E.D., Ranjithan, S.R., 2001. Decision support tool for life-cycle-based solid waste management. Journal of Computing In Civil Engineering (Jan.).

Jambeck, J., Weitz, K.A., Solo-Gabriele, H., Townsend, T., Thorneloe, S., 2007. CCA-treated Wood Disposed in landfills and life-cycle trade-offs with waste-to-energy and msw landfill disposal, Waste Management, in press, doi:10.1016/j.wasman.2007.02.011.

Komilis, D.P., Ham, R.K., 1999. Predicting carbon dioxide and ammonia yield during composting of individual municipal solid waste components and mixtures of components. Proceedings of HELECO '99 Technical Conference. Technical Chamber of Greece, Thessaloniki, Greece.

Komilis, D.P., Ham, R.K., 2000. A laboratory method to investigate gaseous emissions and solids decomposition during composting of municipal solid wastes. Compost Science and Utilization 8, 254-265.

McDougall, F., White, P., Franke, M., Hindle, P., 2001. Integrated Solid Waste Management: A Life-Cycle Inventory, 2nd ed. Blackwell Science, Oxford.

Kaplan, Ö., Barlaz, M., Ranjithan, R., 2005. A Procedure for Life-CycleBased Solid Waste Management with Consideration of Uncertainty. Journal of Industrial Ecology 8 (4).

Solano, E., Ranjithan, S.R., Barlaz, M.S., Brill, E.D., 2002a. Life-cyclebased solid waste management. I. Model development. Journal of Environmental Engineering (October)

Solano, E., Dumas, R., Harrison, K., Ranjithan, S.R., Barlaz, M.A., Brill, E.D., 2002b. Life-cycle-based solid waste management. II. Illustrative applications. Journal of Environmental Engineering (October).

Thorneloe, S.A., Weitz, K.A., 2001. US Case Studies using MSW DST. In: Proceedings Sardinia 2001, Eight International Waste Management and Landfill Symposium, Cagliari.

Thorneloe, S.A., Weitz, K.A., 2003. Holistic approach to environmental management of municipal solid waste. Proceedings Sardinia 2003, Ninth International Waste Management and Landfill Symposium. CISA publisher, Cagliari. 
Thorneloe, S.A., Weitz, K.A., 2004. Sustainability and waste management. In: Proceedings from Sustainable Waste Management, Waste Management Association of Australia, Nov 24-26, 2004, Melbourne, Australia.

Thorneloe, S.A., Weitz, K.A., Barlaz, M., Ham, R.K., 1999a. Tools for Determining Sustainable Waste Management Through Application of Life-Cycle. Assessment: Update on US Research, Sardinia 99, Seventh International Landfill Symposium, vol. V, pp. 629-636, Oct 4-8.

Thorneloe, S.A., Roqueta, A., Pacey, J., Bottero, C., 1999b Database of Landfill Gas to Energy Projects in the United States. In: Proceedings Sardinia 1999, Seventh International Landfill Symposium, Cagliari.

US EPA, 1997. EPA's Compilation of Air Pollutant Emission Factors, Volume I Stationary Point and Area Sources -AP-42, Chapter 2, Solid Waste Disposal. <http://www.epa.gov/ttn/chief/ap42/index.html>.

US EPA, 2003a. Characterization of Municipal Solid Waste in the United States: 2001 Update, EPA530-R-03-011, October 2003. <http:// www.epa.gov/epaoswer/non-hw/muncpl/facts.htm>.

US EPA, 2003b. Beyond RCRA - Waste and materials Management in the Year 2020, EPA530-R-02-009, April 2003.

US EPA, 2004. Resource Conservation Challenge - A Year of Progress, EPA530-R-04-001, February 2004.
US EPA, 2005. Municipal Solid Waste Generation, Recycling, and Disposal in the United States: Facts and Figures for 2003, EPA530-F05-003. Available at: <http://www.epa.gov/msw/pubs/msw03rpt.pdf $>$.

US EPA, 2006. Application of Life-Cycle Management to Evaluate Integrated Solid Waste Management Strategies, Prepared by RTI International for US EPA's National Risk Management Research Laboratory, Research Triangle Park, N.C. Available at: <http:// webdstmsw.rti.or>.

US EPA, 2007. Map of U.S. Landfill Gas to Energy Projects, Office of Air and Radiation. Available at: <http://www.epa.gov/lmop/docs/map.pdf>.

Weitz, K.A., 2003. Life-cycle inventory data sets for material production of aluminum, glass, paper, plastic, and steel in North America. Available at: <https://webdstmsw.rti.org > .

Weitz, K.A., Thorneloe, S.A., Nishtala, S.R., Yarkosky, S., Zannes, M., 2002. The Impact of Municipal Solid Waste Management on GHG Emissions in the United States. Journal of the Air and Waste Management Association 52, 1000-1011.

White, P., Franke, M., Hindle, P., 1995. Integrated Solid Waste Management: A Life-Cycle Inventory. Blackie Academic \& Professional, Glasgow.

Weitz, K.A., Barlaz, M.A., Ranjithan, S., Brill, E.D., Thorneloe, S.A., Ham, R., 1999. Life cycle management of municipal solid waste. International Journal of Life Cycle Assessment 4 (4), 195-201. 